\title{
The challenges of supplying good quality and useful data for significant projects
}

\author{
M Beth Soldata Group, France \\ E Audigé Soldata Oceania Pty Ltd, Australia \\ C Fagan Soldata Oceania Pty Ltd, Australia
}

\begin{abstract}
Geotechnical, structural and environmental monitoring is becoming a standard requirement on construction, civil engineering and mining projects. With the amount of data to be handled, the quantity of stakeholders and the number of projects increasing very rapidly, the quality and usefulness of monitoring can sometimes be compromised. This paper reflects on the key factors influencing the success of a monitoring project. It aims at helping to convince decision makers to make the right choices when dealing with monitoring.
\end{abstract}

The first steps in a monitoring program are design and specification. The authors recommend that the design is carefully thought through, on a site per site and risk per risk basis, so that the correct number and type of instruments are specified.

Defining and reserving a sufficient budget for the monitoring is paramount. Unfortunately, too often an inadequate budget leads to money being spent vainly on useless monitoring.

The choice of the company in charge of the monitoring must never be based solely on direct cost. This is unfortunately often the case for private contracts. On public contracts, however, there is a trend towards trying to apply the best for purpose rule, even if the decision process remains a complex task.

During monitoring project implementation, the engineer or the client should ensure that they have the will, the power, and the tools to demand high quality data. This can only be achieved if the monitoring rules are previously planned and well defined at the specification stage.

The experience and dedication of the monitoring team has a huge impact on data quality.

Instrument installation and readings must be carried out according to predefined methods and quality control procedures. Both manual and automatic instrumentation must be implemented, their ratio depending on the site specific characteristics.

Finally, the monitoring tools usually contained within the monitoring database software must bring added value to help the stakeholders understand the state of their project and risks involved. This includes data fusion (mixing data of different types), alarm management, dashboard and weather map presentations and a journal of events and reporting tools.

\section{Introduction}

In about the last 15 years our world has entered both the digital age and the no-risk age (Beth et al. 2011).

As a consequence, the amount of monitoring data acquired has multiplied by a factor of $10^{2}$ to $10^{4}$ on urban construction sites and slope stability projects, and even more in the mining industry.

However, how do we ensure efficient use of these measurements and assist the users to gain situational awareness and reduce uncertainty? We have seen in recent history that some monitoring projects have not provided added value and/or did not perform according to plan. Such projects cast doubts over the real intentions of monitoring or over specific monitoring techniques. In the years following a failed monitoring 
project, the relevant engineering and construction community and sometimes industries further afield, may be dismissive of monitoring in general or one technique in particular.

Practitioners involved in Field Measurements in Geomechanics Symposia (FMGM) should help to avoid such failed monitoring projects, for everybody's sake.

This paper reflects on the various levers one can act upon to ensure monitoring data are useful and provide added value. It will not provide any major breakthrough in monitoring technics, but FMGM actors might find it useful when trying to convince executives to make wise decisions.

What is detailed herein represents the viewpoints of monitoring practitioners with over 20 years' experience. It does not, however, intend to replace essential documents written by experts or by panels of experts, such as 'Monitoring Underground Construction, a Best Practice Guide' (British Tunnelling Society 2012) or 'Geotechnical Instrumentation for Monitoring Field Performance' (Dunnicliff 1993).

\section{$2 \quad$ Monitoring project preparation}

This section describes the work generally carried out by an engineering company (the engineer), on behalf of the client (the owner).

Note: Often, the actual monitoring work will later be entrusted to two other parties: the main contractor (building the work); and the monitoring contractor (in charge of the implementation of the monitoring project).

There are various ways the engineer could be involved in the preparation of a monitoring contract, ranging from an individual working for the owner, to a specialist monitoring contractor working on a specific design contract. Most commonly, the engineer in charge of the site construction is also in charge of the monitoring design.

\subsection{Monitoring program design}

The key point for design is to understand the geotechnical and structural behaviour of the site. An instrumentation project must be designed in conjunction with the geotechnical and structural design of the structure and its environment. The engineer should list the risks they want to cover and the questions they want answered. References Association Francaise de Normalisation (2014) and Dunnicliff (1993) agree that each instrument or group of instruments shall be aimed at answering at least one specific question, on one specific problem.

Typical questions might be the following: The design assumes the water table is at a depth of $3 \mathrm{~m}$ and expects $12 \mathrm{~mm}$ of ground surface movement; is the retaining wall behaving as calculated? Is the water table where it was expected? Will the neighbouring buildings move by less than $10 \mathrm{~mm}$ ? What are the additional stresses generated by the settlement on neighbouring buildings?

These questions will in turn lead to the type of instruments selected and to the frequency of monitoring required. On the basis of these general needs, the engineer will then write the monitoring specifications (the monitoring plan in Association Française de Normalisation 2014). After European Standard 2004 (EN 1997-1) and European Standard 2007 (EN 1997-2), the monitoring plan should indicate:

- The purpose of each set of observations or measurements.

- Parts of the structure to be monitored and where these measures are to be made.

- How the results will be assessed.

- The range of values where one expects to find the results of measurements (by reference to the observational method).

- The time period during which the measurements should continue after the end of construction. 
- The parties responsible for measurements and observations, interpretation of monitoring data and instrument maintenance.

In the following paragraphs, we describe some errors that have occurred on previous projects.

\subsubsection{Design copied from one project to the next}

A commonly seen mistake is when the monitoring design of project $A$ is copied, totally or in part, to projects $B, C, D$ and $E$.

As this is done without sufficient analysis of the project-specific questions to be answered, the monitoring system is unlikely to be suitable.

Consequences will be either:

Under design: The design is not answering the needs of the new project; some instruments are absent or under designed. A typical example is when sporadic manual readings are requested, when clearly an automatic system is required. Consequently, the risks onsite are not adequately covered, giving rise to potential incident or accident, perhaps catastrophic.

Over design: Contrary to what one might think, this is seen nearly as often as under design. In such cases, instruments are installed that were not really needed. The end result is that stakeholders will view the monitoring as an un-necessary expense, and not as it should be - a risk minimisation tool. In the medium term, such practices will harm the monitoring community and may be an impediment to progress of best practice.

\subsubsection{Design based on habits}

This is a variation of the previous section. It is clearly visible when one has access to monitoring designs from around the world: the geographical specialities of a monitoring program design, based on local habits, are obvious. It is common human behaviour for actions to be based upon experiences, and this behaviour should not be criticised. Generally, the consequences are not as harmful as for design copying; however, they lead to a loss of best practice. Common examples could be as follow.

In some countries, it is the norm to over-drill inclinometer tubes a few metres below the toe of retaining walls for urban excavations. This method minimises the risk of not detecting a movement of the toe of the wall and also helps in detecting potential reading errors. Whereas in other countries, the tube is commonly set only within the retaining wall, which assumes that the toe is fixed.

In some regions, all newly built tunnels include strain gauges cast inside concrete lining segments, to measure the loads transmitted both by the soil (radial load, gauges installed tangentially in the segments, generally in pairs intrados and extrados) and by the tunnel boring machine (TBM) jacks (axial load, gages installed parallel to the tunnel axis, either in pair intrados and extrados or alone in the middle of the segment). These measurements have proved particularly useful. Yet in other parts of the world, such monitoring methods are never specified.

Monitoring may still be specified using older techniques, when newer and proven techniques would provide much better risk management through better precision and higher measurement frequency. For example, weekly manual survey is still found in some specifications, in cases where the risks and the potential onset of occurrence of the risks would suggest that automatic monitoring would be more appropriate. Tunnel construction can lead to rapid settlement and hourly reading, rather than weekly may be appropriate in a city environment. A mine pitwall can fail within hours, suggesting a mix of ground-based radar and automatic motorised total stations (AMTS) may be necessary. ITAtech (2014) provides more details on the specific subject of monitoring frequency. 


\subsubsection{Unproven technologies}

New techniques should only be applied when they bring added value to the project, and when they really help to answer specific questions. Of course, the new technique's promoters will find real or sometimes oversold added value. One should verify if the new proposed technique improves the cost-benefit ratio for the project. It is not uncommon to see new products that bring added complexity and uncertainty, rather than added value.

However, it would be unwise to systematically disregard new techniques and technologies. The last 20 years have shown that new technologies have brought significant added value to slope monitoring in open pit mines and to urban excavation monitoring (Beth et al. 2011). The key points are:

1. A real objective is added value.

2. A real objective is product readiness. It is a good idea, where possible, to trial a new technology in parallel to an existing technology. Redundancy is a standard recommendation in monitoring design (ISO 2014), and it becomes almost compulsory when trialling new products.

3. Open mindedness. New technologies force us away from old habits, sometimes for the best.

\subsubsection{Monitoring budget}

Simultaneously with the monitoring specifications, the budget allocated to monitoring is to be defined. Often underestimated, sometimes forgotten, the budget allocated to the monitoring will have a major influence on the quality and usefulness of the data that will be obtained.

For geotechnical construction, a general rule-of-thumb is that 1 to $2 \%$ of the construction budget (civil budget only, excluding finishes) is generally adequate for a comprehensive monitoring program. Monitoring costs do not greatly impact the global budget of a construction project. With proper monitoring put in place, the risks can be significantly reduced, therefore potentially saving huge amounts of cost-overrun. Alternately, if the monitoring budget is too low, the data provided may be of poor quality that will be un-usable; therefore, whatever small amount was spent on the monitoring will be wasted money.

Too often, clients or contractors try to squeeze whatever monitoring is possible within a given predefined budget, rather than assess the actual cost of monitoring that will help reduce uncertainty and benefit the overall project, both operationally and financially.

\subsection{Monitoring specifications}

The way in which the monitoring specifications are written will have a key influence on the degree of success of the monitoring project.

A publication from the British Tunnelling Society (2012) provides very useful information.

The major considerations that can help increase the quality of the measurements are as follows:

- List clear objectives; if possible, list the engineering values to be obtained, the frequency and the required precision.

- If possible, give liberty to the specialists to select the monitoring system they will use to answer these objectives. The engineer cannot be an expert in all the techniques he or she may specify. By leaving some liberty to the specialists, the best value for money solutions will be determined.

- The required monitoring precision should be the achievable onsite precision, not the instrument's laboratory precision. If possible, the definition of the precision should be detailed, and also the way it can be measured. Some liberty can be taken with the official international vocabulary of metrology, in order to define something that could be estimated. For example, the precision might be defined as the band containing $70 \%$ of the values during 12 consecutive hours with no work. If what is being measured can be affected by temperature, then the 12 hours might be selected when the temperature varies by less than, say, $10^{\circ} \mathrm{C}$ (e.g. building movement). 
- The required precision should be at a level that is necessary and reasonable. Do not over-specify, as those contractors who wish to comply with the specifications will see increased cost, and those who disregard the specifications will end up winning the job. Sometimes we see requirements for $0.1 \mathrm{~mm}$ precision when 0.5 or $1 \mathrm{~mm}$ would be sufficient. Again, the definition of the precision is very important.

- Ideally, clarify how you will enforce the requirements, and plan and make clear some financial penalties in case of non-delivery. Non-delivery includes precision, time without measurements etc. Again, be careful to specify conditions that are reasonable. For example, be aware that if you ask for continuous measurements and you request that any breakdown be repaired in less than four hours, the service cost will be very high for those who respect the specifications. Indeed, the contractor will need to plan to have one or more highly trained specialists, be equipped with all repair and replacement equipment, be paid on-call and probably housed in close vicinity to the project.

\subsection{Monitoring by whom?}

This is a recurrent question within our community. It mainly applies to construction work and is less relevant usually for assets monitoring such as dams or mining.

In general, for the monitoring contractors and the FMGM community recommend that a specialist company working for the owner or for the engineer should carry out the monitoring (the monitoring contractor). This helps to ensure that priority is given to data quality rather than cost or operational constraints. Many publications are defending this position. Although the authors are in full agreement and completely defend this arrangement, they will not bring much added value by detailing our arguments here.

It should be noted that a proportion of owners, engineers and main contractors prefer to attach the monitoring contract to the main construction contract. The monitoring is then carried out by a monitoring contractor working as a subcontractor to the main contractor, or sometimes by the main contractor themselves. The defendants of this solution explain that this way the full responsibility is given to the main contractor, and also that interfaces between construction work and monitoring tasks are better managed.

AFTES (1998) lists the pros and cons of both solutions in French. Vargas and Beth (2014) detail the same ideas in English.

\section{$2.4 \quad$ Monitoring procurement}

This is not an easy subject; it is a subject upon which it is difficult to provide neutral and impartial advice. The choice of a monitoring service provider is influenced by many factors, amongst which are:

- The proposed price of the service. Unfortunately this is still a key factor, and when the cost difference between companies is large it is difficult not to contract the lowest. Other considerations, as described in this paper, should be taken into account.

- The proposed quality of service. Of course in an ideal world the selection of a company would be based essentially on its ability to deliver exactly what is needed for the job. In reality it is difficult to assess a proposal and whether the proposer will be capable of delivering its promises. Past experience and references are then key.

- The political environment. For example, there might be some pressure to favour local contractors or to share the projects between contractors.

- Last but not least, the personal feelings and other human factors.

In the list above, we mentioned the ability to exactly deliver what is needed for the job. It is important to remain focused on the needs for that job. The proposing company should avoid pushing forward additional 
features or services that are not really necessary, and the body judging the offers should try not to be influenced by those.

The point that the authors stress to the monitoring community is that systematically selecting the lowest bidder is not recommended. There exist many papers and editorials on the subject; we will not pursue that point here. Globally, our impression is that the subject is now considered carefully on public tenders in Europe, but that selection of the low bidder remains more or less the rule in private contracts.

On public tenders, the persons in charge of selecting the monitoring company try to take into account the quality of the proposed service. Often the marking process allocates, say, 50 or $60 \%$ of the points to the technical analysis. Sometimes the technical and financial marks are given by different persons, independently. The whole procedure remains subject to adapting the technical marks to suit the price preference or the political or human preference, especially when the technical marking process is not clearly defined beforehand. However, it seems efforts are made. We give here three real examples.

Example 1: Company A was the lowest bidder on this tender, $20 \%$ lower than the second lowest bidder, Company B. However, after technical analysis and applying technical marks, Company B won the contract. Of course, Company A was not happy, thinking that they were disregarded for the wrong reasons. But it shows an example where clear marking rules were applied, and the estimated best for purpose bidder was selected.

Example 2: The client received eight tenders. Company A ranked fourth in price, with prices ranging from a ratio of 1 to 3.5. The highest bidder was $225 \%$ above the lowest bidder, with other bidders spread out in between. The offer from company A was $75 \%$ above the lowest bidder. With such high variation, the client requested technical clarifications from all eight tenderers. After careful analyses and technical marks were applied, the contract was finally awarded to Company A.

Example 3: The client received four tenders, of which only two were judged to be technically acceptable. Company B was exactly on the client's budget. The price of Company A was more or less twice that value. The technical marks were exactly opposite, and on the sum of technical and financial mark, both offers were very close. Company B was selected. However, after a while the client finally had to cancel the contract and appoint Company A to help finish the work. This is another example showing the complexity of the procurement decision. The initial filter based on competencies had been carried out, leaving just two competitors. The technical analysis had been carried out. But the price difference was so high that it was difficult not to go for the lowest bidder.

For each of these examples, we can see that technical value is taken into account in the public tendering analysis and that judging the best for purpose is a difficult art. We can also see that a correct initially anticipated budget helps in selecting the best for purpose contractor. It is much easier to judge impartially on real quality for money when the allocated budget is sufficient to cover more than just the lowest bidder.

Unfortunately, with the private sector it seems that very often the low bid process is still the norm. This fact gives further credibility to the argument that the monitoring contract is better placed directly with the owner rather than through a contractor.

The financial pressures are probably higher in the private sector; therefore, the selection of a monitoring contractor other than the low bidder is a difficult decision. At best, what we sometimes see is that the client will ask the preferred bidder (based on technical analysis) to lower their price to that of the low bidder. This method carries its risks, as the preferred bidder will need to adjust their level of service to the budget the client has been allocated.

One could also say that it is up to the monitoring contractors to avoid low bidding. Again, it is a complex decision to decide on the financial limit below which it is better not to do the job, below which accepting the rebate would mean not being able to provide correct data, thus putting both the job and the company's reputation at risk. 
Note: In this whole section, one could replace 'public tender' with 'directly with owner' and replace 'private' with 'contractor'. However, the extension is only partially true in our experience, so we have not applied it.

\section{$3 \quad$ Project supervision}

\subsection{Enforcing specifications}

It is important for the client and their engineer to ensure they have the power to demand high quality data during the project duration.

Without proper and strict supervision, it is a fact of human nature that the level of service can degrade and the priority is placed on those who ask louder, such as the client or company asking for lower costs; the main contractor asking for lower disruption to the production; or another client requesting more attention to another job etc.

A continuous level of respect for the specifications is therefore an essential requirement. This is only achievable if the specifications are correctly written and adapted to the project needs. If the specifications state clearly the rules, enforcement and verification of those rules will be a much easier task.

Financial penalties are an effective way to maintain this pressure.

The crucial point is to enforce, during the contract, what was stated in the specifications. It is not as trivial as it may appear - the pressure of day-to-day site activities, the complexity of leveraging a contractor or, even more complicated, a contractor's subcontractor, all lend themselves towards cut-corners and liberties with the specifications and the quality of the service rendered, the quality of the data and the quality of the risk management.

\subsection{A site example}

A perfect site example, as far as specifications/monitoring by whom procurement/supervision is concerned, is the Amsterdam North South Line (NZLljn) construction. The beginning of the project is rather old, as it dates back to the early 2000s, but its peak period in terms of construction monitoring was during 2009-2012.

The specifications stated that there were to be financial penalties when monitoring data was missing. As an example, clear cost penalties were listed for periods when data was missing, depending on the phases of work. At peak periods during tunnel construction, for CYCLOPS prism monitoring within the anticipated zone of influence and within a short distance from the TBM face, penalties applied if a prism was not surveyed within four hours. Clearly, such specifications pushed the monitoring contractor to implement a very rigorous quality control system, to ensure that data was collected at all times. All critical parts of the systems were backed-up, and very attentive on-call procedures were put in place.

During the work, the project supervision was well organised and stringent. To help scrutinise the monitoring, the Engineer had an automatic system that would list any missing data amongst the 10,000+ instruments onsite. Every week a list of the potential problems was sent to the monitoring contractor, with the associated potential penalties. As a result, the monitoring contractor was acutely aware than any failure on his part, even minimal, would immediately lead to financial penalties.

The job ended in 2012 , the monitoring as initially designed proving a success and without any penalty only because of a combination of (i) total commitment from the monitoring team to deliver, (ii) the well-designed specifications, and (iii) rigorous site supervision from the engineer.

Note 1: The monitoring contract was directly with the owner/engineer.

Note 2: Apart from the monitoring, the job did encounter its share of technical difficulties, and additional monitoring was added as new potential risks were discovered. This was the result of unforeseen conditions and is no fault of the quality of the initial design and procedures. 
Note 3: One must be aware that such high focus on quality has a cost. To ensure that any failed system was back online within four hours, a dedicated engineer was required to watch the quality parameters $24 / 7$. In the case of a problem, the engineer would try fixing the issue remotely, before alerting the on-call team for immediate intervention onsite. When the requirements were less stringent and a 12-hour response was allowed, the regular day-shift team would be able to deal with most problems, therefore vastly reducing costs.

\section{$4 \quad$ Project implementation}

After the monitoring job has been specified and awarded, the work needs to be performed.

\subsection{Project team}

Even with modern day automatic instruments, the final quality of the monitoring relies mainly on the quality of the monitoring team onsite. The team personnel should include at least $50 \%$ experienced monitoring engineers and technicians, with say a minimum of five years' experience. The offsite back-up and supervision also cannot be neglected. It is the offsite support that should quickly smooth-out any site difficulty, and it is the offsite supervision that should steer the team towards a high quality of service.

\subsubsection{Project management}

The project manager on a large monitoring site acts as the leader for the whole team. Their approach to the preparation of the site activities and attention to data quality are key to the success or failure of the monitoring.

The project manager is in a difficult position in that they are also the guarantor, on behalf of his company, of the financial success of the project. A good project manager will understand the necessary balance between financial and technical success, and will spend a little more when necessary for the proper functioning of the operations they are leading.

For large monitoring sites, say for those with more than ten employees, the project manager could in theory be inexperienced in monitoring, as their tasks could be disconnected from direct monitoring operations. However, in general we recommend that the project manager comes from the monitoring discipline, having evolved through the various positions and levels, knowing thoroughly the intricacies of the tasks they will manage.

\subsubsection{Operator experience and training}

The team should be trained regularly to perform tasks in an optimum manner. Many monitoring tasks appear simple at first but can easily lead to false results when not carried out properly. A typical example is manual inclinometer surveys. Some companies could be tempted to assign this task to completely inexperienced operators, with pressure on productivity as the main focus. Such apparently simple and repetitive tasks can be easily compromised for various reasons, such as not keeping the height reference constant through successive surveys.

The manual inclinometer example leads us to the technical component. At least one engineer, not necessarily the project manager, with at least 10 years' experience in monitoring, should be based onsite, or offsite if allotted sufficient time to be able to supervise regularly the quality of the work. Their tasks will be to train the team to check their readings, to detect their own mistakes and to be capable of solving any specific technical difficulties.

It is desirable to have a good proportion of the monitoring team, and especially those in direct contact with the client, coming from a formal geotechnical or civil engineering background. The quality of the monitoring service is significantly increased when what is being measured is understood. When an event is measured onsite, the engineer must be able to ascertain its plausibility, to validate the readings, and subsequently to be able to discuss with the client potential reasons for the event. Similarly, it is important 
to have a good knowledge of construction methods, which allows an understanding of the needs of clients, and allows the optimal monitoring solutions or implementation procedures to be proposed. Of course, other specialities may also be needed in the team, like electronics, computing, mechanics, surveying.

The challenges of supplying good quality and useful data for significant projects therefore stem from being able to source, train and manage the right monitoring team.

The monitoring world has been continuously expanding for at least the past 15 years, and continues to do so, driven by the pursuit of limiting the risks associated with large infrastructure projects. This means that monitoring companies are continuously recruiting and training new people, a complex task in itself. There have been examples of companies growing too rapidly or taking on jobs too big for themselves and ultimately failing to deliver. It is difficult to draw a line between sustainable growth (to ensure recurring interest and professional development can be provided to teams) and growing too fast.

Another challenge is monitoring jobs appearing in new locations across the world. For financial reasons at least a proportion of the project team must usually be employed locally. The difficulty becomes the ability to locate trained engineers and technicians with at least two years of experience in close proximity to the site.

\subsubsection{Company culture}

The team onsite as well as the support team are heavily influenced by the mindset of their company and hierarchy.

There are examples of where the team members onsite were motivated and hardworking-working, but lacked the proper tools and staffing to obtain good quality readings.

The search for data quality must be at the forefront of the whole hierarchy to ensure the proper decisions are taken, even in difficult times.

\subsection{Instrumentation and systems installation and configuration}

For many instruments, poor quality of installation will render future measurements impossible or will deliver very poor quality data. Manual inclinometers are again a good example. You can have the best personnel onsite taking readings and validating the data, but if the inclinometer tubes are poorly installed, there is little the monitoring team can do to overcome this.

The fact that the instruments are installed over the first weeks and months of the project, when the teams are not completely formed, and the organisation can still be in disarray, complicates the situation further. Jobs can often be awarded much later than is desirable, so the project team is already behind schedule before they arrive onsite.

This is when proper procedures and quality control on the installations become paramount. Training and supervision are also crucial, at a period when the site team is often not fully operational.

Ideally, final control sheets are put in place, which list, for each instrument, the quality control to be carried out. When possible the control consists of applying a known variation to what is being measured, and checking on the final client's screen whether the variation is correct. It is surprising how many mistakes can be detected using this method. Typically, these include:

1. Factor of $10,100,1,000$, or $1 / 10,1 / 100,1 / 1,000$ on the data. This can typically happen somewhere along the data treatment chain.

2. Inverted sign of the movement. The output of some crack-gauges for a crack opening might be positive for some instruments, but negative for another type or brand. Or positive in the engineering world of one country and negative in another.

3. False orientation of the $X$ and $Y$ axes, either because of different coordinates systems in use onsite or simply because of a calculation mistake. 
In a similar vein, official trial tests can be specified and carried out, in the presence of all parties concerned. This is the external version of internal final control sheets, where the monitoring specialists must prove the good functioning of their system in normal and degraded conditions. For example, a system of three AMTS units is set up working in a group. Then for each tested event, the results are verified on the monitoring database. Events could include:

- Moving one monitoring prism by a known distance and observing the value indicated by the database.

- Moving one reference prism and observing that the data remains correct on the other prisms and receiving the system alarms.

- Moving one total station and observing that the data remains correct for all prisms.

- Removing one of the three stations and observing that the remaining two continue to provide results, and receive system alarms and data quality alarms.

\subsection{Quality control on measurements}

Data is provided either by what might seem simple manual readings or by automatic systems. Many clients request the reason for having data managers and data control expenses onsite. Some clients also do not want to pay for anything once the instruments have been installed. A common comment is that the instruments are automatic, so you do not need anybody onsite.

The truth is that without daily quality control, the systems, whether manual or automatic, will quickly drift. The reasons are numerous. For manual readings they can be:

1. Change of operator onsite.

2. Change of procedure, by mistake or by lack of attention.

3. External event on the instrument, shock, weather etc.

4. Wear and tear of the equipment.

5. Error.

For automatic readings:

1. External event on the instrument, shock, loss of power, cable cut, obstruction of the lines of sight, seasonal variations etc.

2. Wear and tear of the equipment.

3. Software malfunction.

4. Change in the assumptions, in the reference system, e.g. the reference points of a surveying system start to move or the reference point of a borehole extensometer starts to move.

A tight and continuous quality control system is necessary. How can one provide this, when on large monitoring sites there might be tens of thousands of points measured every hour? In such cases, it is necessary to put in place automatic checks on the data. Such checks can be very basic, e.g. to check whether the data is included within predefined bounds. But the check can also be complex and bring a degree of artificial intelligent support to the monitoring engineers.

A typical example is automatic motorised total stations. The checks that would normally be carried out by experienced and conscientious surveyors on manual data have been automated and the data can be either disregarded or flagged out and/or can trigger a system alarm, if some advanced parameters exceed limits. These can include the number of reference points available, the percentage of prisms read, the overall least square quality parameter, the stability of the reference points (checked using loop verifications). More details can be found in Beth and Obre (2005). 
Another example is analysis in real-time of the automatic instrument's values, typically the standard deviation of the data, to detect any change in statistical parameters.

The automatic algorithms cannot do everything; human brain power is necessary. Data managers receive the automatic system alarms, but they then need to analyse the alarms and conduct corrective actions if necessary. They also need to check the manually acquired data, such as manual inclinometer readings. Finally, they are in charge of carrying out advanced punctual checks and detailed quality checks. An instrument or a group of instruments is selected and an in-depth analysis of the data from its internal parameters to the final plausibility of the engineering values is undertaken. The aim of these in-depth checks is to detect faults that could have been missed by the previous filters.

\subsection{Maintenance}

The maintenance of instruments and systems goes hand-in-hand with the quality control.

Maintenance can be proactive, reactive or non-existent. In the latter case, without any maintenance, some automatic sites may cease to operate after a couple of weeks without intervention.

Depending on the accepted level of risk and sufficient spare parts, redundancy must be provided and included in the budget, and a sufficient number of competent technicians made available.

The ability to log on a site journal all of the maintenance activities and improvements on the system being performed will allow the monitoring engineer to put in place a proactive maintenance system, thereby reducing the risk of potential data gaps.

Proactive maintenance also includes having prepared a risk analysis of the potential failures of the monitoring system, with a corresponding action plan to correct each item.

\section{$5 \quad$ Added value}

The primary deliverable of any system is valid measurement data.

It is assumed that the client, engineer and main contractor are receiving good quality data. This is a major achievement in itself. But the next question to address is: How can the usefulness of the monitoring data be maximised for the users, considering that data is useless without analytics?

The three key deliverables of a monitoring system are:

1. Real-time alarms.

2. Data analysis capabilities.

3. Comprehensive reports.

\subsection{Data integration and data fusion}

\subsubsection{Data integration}

All data shall ideally be integrated in a single shell, whatever the source, format, acquisition frequency for global analysis. A common mistake, for example, is to have data from automatic and manual acquisition systems managed and displayed in different platforms.

This feature also applies in mining for slope stability monitoring where radars, laser scanners or InSAR measurements are now commonly used. Integration in this instance implies that the monitoring system can handle large quantities of data, as those systems can yield many tens-of-thousands of measurement points every few minutes.

Data integration can also go beyond the traditional scope of monitoring to include information from third parties that are important for the analysis and understanding of the given situation. In the tunnel construction arena, for example, acquisition of a selection of TBM parameters has proven to be very 
valuable. These key parameters include the face position, the pressure(s) at the face, the grouting pressures, the muck volume and the muck weight. In the mining industry, for example, the dynamic positions of loading shovels and blasting can be of great value when analysing slope stability.

\subsubsection{Data fusion}

Cross correlation of information from different sources is a good way to overcome the limitation of a given technology and/or confirming an evolution or data trend. Creating virtual sensors by a combination of real sensors enhances analytics and significantly helps to avoid false alarms. Through such measures, robustness of the information is improved, and more information can be obtained.

The comparison of prism (AMTS) and radar data in mining is a good example.

In tunnelling, the real-time calculation of the face volume loss value can bring the added value of a simple and global parameter.

Combining AMTS readings of building facades in a street with liquid levels or electrolevels inside of the buildings allows absolute elevation information to be transferred inside the buildings.

\subsection{Real-time alarms and communication}

The provision of real-time alarms will provide added value to the stakeholders. A state-of-the-art alarm management system should obviously trigger an alarm based on abnormal situations according to the configuration and, equally as important, avoid false alarms. To achieve this, experience has shown that the monitoring systems, and mainly the software, must be provided with the following key characteristics.

\subsubsection{Alarm and data velocity}

Once triggered, an alarm must be promptly delivered to the stakeholders along with the necessary information to immediately assess the severity of the alarm. This is the notion of data velocity, where alarm and relevant trend data must be accessible anytime, anywhere to anyone who has the right to receive it. Data velocity to smartphones and tablets plays an important role.

\subsubsection{Alarm management}

The monitoring system should be provided with full traceability associated to user rights management. Is the alarm still running? Has it been acknowledged? Who acknowledged it? What is the attached comment/justification? Who has the rights to acknowledge alarms and what types?

\subsection{Data analysis}

Once an alarm has been triggered - or even if there is no alarm - the ability to efficiently analyse the data to support decisions is a key and necessary capability of a monitoring system. Many features and tricks can help.

\subsubsection{Weather map approach and dashboard}

The weather map approach is the ability to display, in a very simple and effective way, a huge volume of more or less complex data so one can understand what is going on at a glance. Think of the weatherman on television. He explains in one minute the results of some of the most complex monitoring and data calculations that exist, in a simple way that everybody can understand. In our business, the engineer must rapidly grasp the results of thousands of measurement points from the field. By extrapolation, using the same kind of interface for a smaller number of inputs can be very effective as well. Figure 1 illustrates a representation of the settlement of a road during a tunnel construction. Even with the low resolution of this image one can understand immediately what is happening. 


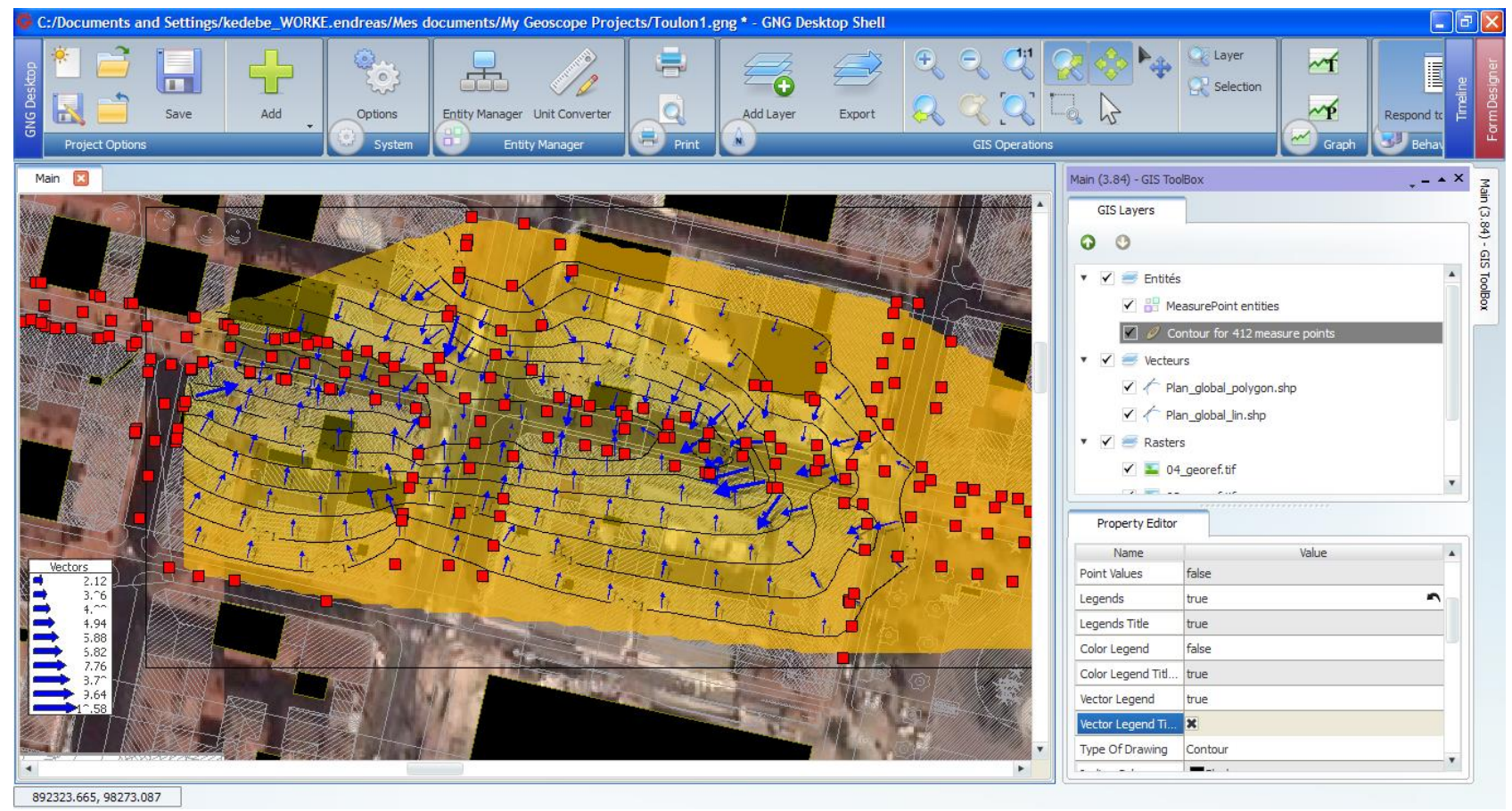

\section{Figure 1 Example of a weather map display of settlement}

The dashboard concept is similar in that a summary of activities from around the site are shown on one page. Typically, the number of alarms of each type of instrument per zone is shown, along with a plan view of critical project areas. By simply clicking on the information, the user can then, if they so wish, drill down into the data to better understand the trends and what might have caused an exceedance.

\subsubsection{Journal}

The construction of large infrastructure projects and the operation of mines are arenas where many events can occur that might have an impact on the monitoring data. Some such examples include heavy rain, rock falls, increased rate of excavation, temperature variation etc. Analysis of the monitoring data without taking into account such events may hinder the outcome, and in worst-case scenarios, lead to false conclusions. The monitoring system provided must be capable of recording and retrieving a journal of events when displaying or analysing the data. This journal of events should be accessible whenever using tools such a graphs or reports involving the affected monitoring points.

\subsection{Reporting}

Reporting is the ultimate deliverable in the monitoring process-chain. A report is where the data that has been transformed into information resides and where the selected information is presented in a clear and systematic way to the management team to support decisions. The report must be accurate, complete and clear.

In practice, the time required to create such a monitoring report appears to be a major component of the effectiveness of the reporting module. Too often, the lengthy time taken to prepare a report degrades the effectiveness of the report, as information is not quickly delivered to those who need it. Using a template based structure, an integrated report should not require more than a few clicks (in addition to the insertion of any comments, analysis, or interpretation) to be edited, printed and dispatched to all stakeholders. 


\section{Use of the monitoring results}

The way in which data is presented, the quality of the reports, and the analysis toolbox within the monitoring software, all contribute to help the engineer's understanding of the up-to-date status of the risks onsite.

A successfully executed monitoring project will ensure that preventive or corrective actions are taken in a timely manner when the results differ from those that were anticipated. It is highly recommended to have a response action plan ready, prior to starting the monitoring period, that clearly details for each situation a list of carefully designed actions, along with those responsible for executing such actions. It is too late to put such a plan in place after the fact, as this can lead to confusion, undefined responsibility and poor response action choices. This is a well described aspect of the observational method. Compensation grouting where, for example, small volumes of grout are injected between a tunnel under construction and the surrounding ground to re-compact the ground as excavation proceeds, is a particular and quite specific application of the observational method. Both action plans and compensation grouting are further described in Vargas and Beth (2012).

\section{Conclusion}

The factors influencing the success, partial failure or total failure of a monitoring project are numerous, starting at the beginning during the design phase, through to procurement of the monitoring specialist, installation of the instruments, to data collection, pre-analysis, data presentation and reporting.

The recommended course of action detailed herein presents a sequence of sometimes complex phases which can only be overcome through a combination of monitoring experience and a sense of modesty by all actors involved, from the client to the engineer and the monitoring specialist. All contributors must strive for a high standard of quality through continuous attention to detail and a relentless search for excellence. A single phase overlooked or failed among those presented in this paper can lead to the monitoring project not supplying quality or useful data.

There are eight golden rules:

1. Monitoring program must be designed specifically for the project, justified by the project needs.

2. Adequate monitoring budget. Allocating an insufficient budget might end up in wasted money.

3. Clear monitoring specifications, listing clear objectives including precision, and leaving some degrees of liberty regarding the methods to be used.

4. No low-bid procurement.

5. Clear and strong enforcement of the specifications.

6. Experienced monitoring team, focused on data quality.

7. Quality control on the measurement, and active maintenance of the monitoring systems.

8. Added value tools to maximise the use of the monitoring data.

A monitoring project will only serve its purpose if the information provided helps to identify risks and reduce the geotechnical, structural and environmental uncertainties of the site. If it fails in doing so, the money spent on the monitoring is wasted. Therefore, to obtain good quality and useful data, it is essential to ensure that all boxes are ticked at every step along the lifecycle of a monitoring project.

The paper concludes with a letter from Vauban, written more than 300 years ago. Vauban is a celebrity in France because he constructed fortified cities everywhere, and his constructions are still visible today all over the territory. While he was General Commissioner of Fortifications for France, Vauban wrote the following letter in the year 1683 to the Marquis of Louvois, Minister for Public Works and Secretary for War in the French government during the reign of Louis XIV. Here is a transcription in English of this letter: 
"To Louvois:
My Lord,

There are some remnants of construction works in recent years which are not finished and will never reach satisfactory completion, and all that, My Lord, due to the disorder resulting from the frequent discounts of which there are records in your financial accounts. For it is certain that all these broken contracts, promises not kept, and revision of adjudication only serve to attract towards you as Contractors all those desperate ones with no other place to turn, the untrustworthy, and the ignorant, and to scare away all those who have something valid to offer and who are capable of running an enterprise correctly.

I maintain, in addition, that they delay and increase considerably the final cost of the works which they carry out most badly, because these discounts and bargains that are so sought after by the free market are imaginary, especially so because it is the Contractor himself who also loses out, like a man who is drowning and who grabs at anything he can reach. This Contractor does not pay his suppliers from whom he took the materials; he pays badly the workers whom he engages, cheats all those he can, and can only find the worst ones because they are desperate and allow themselves to be paid more cheaply than others; he uses only the meanest of materials, quibbles about everything, and still cries for mercy against this and that.

This should be enough, My Lord, for you to see the imperfection of this conduct: and then to abandon it in the name of God, RESTORE GOOD FAITH;

GIVE THE FAIR PRICE FOR THE WORKS TO BE CARRIED OUT AND DO NOT REFUSE AN HONEST WAGE TO A CONTRACTOR WHO PERFORMS HIS DUTY, THIS WILL ALWAYS BE THE BEST VALUE THAT YOU CAN EVER FIND.

I remain, My Lord, with all my heart, your very humble and very obedient servant,

Sébastien Le Prestre de Vauban, Maréchal de France, (Archives nationales de Paris). 17th July 1683."

\section{References}

AFTES 1998, 'Recommandations relatives à l'organisation de l'auscultation des tunnels', Tunnel et ouvrages souterrains, vol. 149.

Association Francaise de Normalisation 2014, NF EN ISO 18674:2013: Geotechnical Investigation and Testing - Geotechnical Monitoring by Field Instrumentation - General Rules, Association Francaise de Normalisation (AFNOR), Paris.

Beth, M \& Obre, X 2005, 'Ground movement monitoring at Kings Cross Station, London', Proceedings of the Institution of Civil Engineers - Geotechnical Engineering, vol. 158, no. 3, pp. 125-133.

Beth, M, Pezzetti, G \& Schmuck, C 2011, 'Urban Excavation Instrumentation: Analysis and reflexions', Proceedings of the Eighth International Symposium on Field Measurements in Geomechanics, Technische Universität Braunschweig, Berlin.

British Tunnelling Society 2012, 'Monitoring underground construction: a best practice guide', ICE Publishing, London.

Dunnicliff, J 1993, Geotechnical instrumentation for monitoring field performance, John Wiley \& Sons, Inc., New York, NY.

European Standard 2004, EN 1997-1 Eurocode 7: Geotechnical Design - Part 1: General rules, European Committee for Standardization (CEN), Brussels.

European Standard 2007, EN 1997-2 Eurocode 7: Geotechnical Design - Part 2: Ground Investigation and Testing, European Committee for Standardization (CEN), Brussels.

ITAtech 2014, ITAtech guidelines on monitoring frequencies in urban tunnelling, report N³-V2, ITAtech, Lausanne.

Vargas, B \& Beth, M 2012, 'Observational method using real time surface settlement monitoring: the South Toulon Tunnel Project', in RD Hryciw, A Athanasopoulos-Zekkos \& N Yesiller (eds), Proceedings of GeoCongress 2012, American Society of Civil Engineers, Reston, VA, pp. 3109-3118.

Vargas, B \& Beth, M 2014, 'Urban tunnel monitoring: what's next?', in G Davidson, A Howard, L Jacobs, R Pintabona \& B Zernich (eds), Proceedings of the North American Tunnelling, Society for Mining, Metallurgy \& Exploration, Englewood, CO, pp. 42-48. 
